\title{
Impact of family social support on psychological wellbeing of infertile women attending Yusuf Dantsoho Memorial Hospital, Kaduna, Nigeria
}

\author{
Abubakar R, ${ }^{1}$ Zubairu HD, ${ }^{1}$ Yohanna $\mathrm{S}^{2}$ \\ ${ }^{1}$ Department of Family Medicine, Barau Dikku Teaching Hospital, Kaduna; ${ }^{2}$ Department of Family \\ Medicine, Bingham University Teaching Hospital, Jos, Nigeria
}

\begin{abstract}
Infertility could be a life crisis with a wide range of socio-cultural and emotional problems. These social consequences are usually not voluntarily disclosed by the affected women and consequently do not receive adequate attention so the women continue to suffer in silence. The study aimed to determine the impact of family social support on psychological well-being of infertile women attending Yusuf Dantsoho Memorial Hospital (YDMH), Kaduna. The study was a cross sectional study conducted at the YDMH, T/Wada, Kaduna. Two hundred and fifty-four women who presented to the gynecology clinic during the study period and consented to participate in the study were recruited consecutively. Data on socio-demographics and family social support were determined using a self-structured questionnaire. Psychological wellbeing was assessed using a General Health Questioner. Data was analyzed using EPI-INFO statistical package. Majority of the participants were Northerners (70.1\%), Muslims (91.7\%), and Unemployed (52.8\%) with an average monthly income of less than N 20,000 (73.6\%). Most were within the age group of 25-30 years (40.2\%) and from monogamous families $(70.1 \%)$ with most families having $0-5$ children (89.4\%). $67.7 \%$ of the participants had adequate social support from their husbands as against $32.3 \%$ who had inadequate support (such as availability of financial, support
\end{abstract}

Correspondence: Habiba Zubairu HD, Department of Family Medicine, BDTH, Kaduna , Nigeria.

Tel.: +2348068109803

E-mail: zubairuhabibatu73@yahoo.com

Key words: Family, support, psychological, wellbeing, infertile, women.

Contributions: Authors contributed equally.

Conflict of interest: Authors declare no potential conflict of interest.

Ethics approval and consent to participate: Not required.

Received for publication: 18 June 2020 .

Accepted for publication: 20 July 2020

This work is licensed under a Creative Commons Attribution NonCommercial 4.0 License (CC BY-NC 4.0).

CC Copyright: the Author(s),2020

Licensee PAGEPress, Italy

Annals of African Medical Research 2020; 3:118

doi:10.4081/aamr.2020.118 encouragement, concern and sense of social belonging). Only $33.5 \%$ had adequate social support from their in-laws while majority of them $(66.5 \%)$ had inadequate social support. A total of 203 $(79.9 \%)$ of the participants had psychological distress (self-administered questioner) while 51 (20.1\%) had no psychological distress. Husbands and in-laws support were significantly related to psychological wellbeing of the infertile women. Adequate social support provided by family members reduces stress, improves psychological wellbeing and quality of life of infertile women.

\section{Introduction}

Social support is the perception and actuality that one is being cared for, the availability of assistance from other people and belonging to a supportive social network. Perceived social support means gaining information, financial help, health scheme or recommendation and affective support from loved ones like friends, spouse or relatives. ${ }^{1}$

Psychological distress is any range of symptoms and experiences related to a person's internal life; feelings of being troubled, confused or out of the ordinary. ${ }^{2}$

Infertility is one of the most important life crises that women go through. Infertile women experience fear, loneliness, frustration and perceived lack of support because they assume that no one can perceive their problem and empathize with them. This makes them feel rejected and more anxious, making them to avoid social interactions with their family, friends and relatives. ${ }^{3}$

Social support improves well being and quality of life. It also influences the defense mechanisms to prevent various illnesses including anxiety and depression ${ }^{4}$. Social support can reduce negative effects experienced by infertile women through creating new solutions for problems to improve on the individual's self-esteem and self efficacy to cope with the infertility. ${ }^{5}$

Social stressors of infertility may differ according to societal norms. In developed societies, voluntary childlessness is viewed as a viable and legitimate option, and women without children are often presumed to be voluntarily childfree. However, in developing countries, bearing and rearing children are central to women's power and well-being making stigma related to infertility greater. ${ }^{5}$ Social support and coping styles could be helpful in reducing the stress caused by infertility among women. ${ }^{6}$ Social support always has a moderating role in pressures caused by infertility which results in gaining positive feeling. ${ }^{7}$

Qadir et al. showed that focusing on coping strategy and also emphasizing on the family support for infertile women could have an important effect on decreasing their depression and also decreasing their vulnerability regarding the social tag related to infertility. ${ }^{8}$ Khoshbin et al. also showed that increased social support resulted in decreasing the loneliness in infertile couples. ${ }^{9}$ Thus an intimate communication combined with value and respect for the infertile woman results in a feeling of increasing social support 
in them. Parents, family traditions, social norms, and religion all play an important role in the transmission of values and gender roles. The intrusive nature of in-laws constitutes potent sources of stress for infertile women. In Africa, a woman with infertility problems may be despised, neglected and abandoned by her husband and her in-laws. ${ }^{10}$ Families and in particular, prospective grand parents, may place added pressure on infertile daughters-in-law by publicizing their expectations for grandchildren. Enquiries from in-laws can feel intrusive and can be stressful.

Social support is a source of coping and it is of great importance for the infertile woman to help preserve her physical and mental health. Social support is a valuable coping method that contributes to love, affection, confidence, self- expression, self-knowledge and a sense of belonging. Even if it cannot eliminate the stressful situation, it enables individuals to be more optimistic by decreasing their levels of anxiety. It helps individuals in coping with challenging situations and generating new solutions and decreasing their desperation. ${ }^{11,12}$ This study sought to determine the effect of family social support among the participants.

\section{Materials and Methods}

The study was carried in the Gynecology Clinic of Yusuf Dantsoho Memorial Hospital (YDMH), Kaduna, from March to May 2015. A total of 254 participants were recruited during the study period. A non-probability sampling technique was used to recruit every consecutive woman presenting with infertility who consented and met the inclusion criteria (WHO 2013 defines infertility as the inability of a couple to conceive after two years of regular unprotected sexual intercourse). Data was collected using a structured questionnaire containing information on sociodemographic characteristics, family characteristics, medical history and health care financing. Data on family social support was determined by using a structured self-administered questionnaire which assessed family social support such as emotional and financial support by husbands and in-laws as been adequate or inadequate. Psychological wellbeing was assessed by using a GHQ questionnaire. ${ }^{13}$ The GHQ is a validated 12 item structured self-administered questioner that can be used in detecting non specific psychiatric disorders which is a simple screening tool for assessment of psychological well-being of an individual. It is not a diagnostic tool. Data was analysed using EPI-INFO statistical package. ${ }^{14}$

Socio-demographic characteristics such as age, tribe, occupation, average monthly income, level of education, family type and religion, as well as the family social support, were analyzed by means of descriptive statistics. The study showed a significant statistical relationship between family social support and psychological wellbeing of the infertile women.

\section{Results}

The data for all the study participants were analyzed. The majority of the participants were Northerners (70.1\%), Muslims $(91.7 \%)$, and unemployed (52.8\%) with an average monthly income of less than N 20,000 (73.6\%). Most were in the age group of 25-30 years $(40.2 \%)$ and from monogamous families $(70.1 \%)$ with most families having $0-5$ children (89.4\%).

The summary of the sociodemographic characteristics of the study participants are shown in the Table 1 .

\section{Level of social support among the study participants \\ Membership of a social group}

Only two $(0.8 \%)$ of the participants were members of a religious organization. Three $(1.2 \%)$ were members of a cooperative society, while twelve $(4.7 \%)$ were members of a professional group. The majority of the participants, 237 (93.3\%), did not belong to any social group.

\section{Husband's support}

In $172(67.7 \%)$ of the participants, their husbands provided them with adequate social support, as against $82(32.3 \%)$ of the participants whose husbands provided inadequate social support.

Table 1. Socio-Demographic Characteristics of the Study Participants. $\mathrm{N}=\mathbf{2 5 4}$.

Variable Frequency (n) Percentage (\%)

\begin{tabular}{ccc} 
Age group (years) & & \\
$<18$ & 6 & 2.4 \\
$19-24$ & 65 & 25.6 \\
$25-30$ & 102 & 40.2 \\
$31-36$ & 58 & 22.8 \\
$37-42$ & 23 & 9.1 \\
Ethnic group & & \\
Hausa & 178 & 70.1 \\
Yoruba & 28 & 11.0 \\
Igbo & 1 & 0.4 \\
Others & 47 & 18.5 \\
\hline
\end{tabular}

Religion

$\begin{array}{lcc}\text { Christianity } & 21 & 8.3 \\ \text { Islam } & 233 & 91.7\end{array}$

\begin{tabular}{lcc} 
Level of Education & & \\
None & 3 & 1.2 \\
Primary & 69 & 27.2 \\
Secondary & 88 & 34.6 \\
Post-secondary & 61 & 24.0 \\
Qur'anic & 33 & 13.0 \\
\hline
\end{tabular}

Occupation

Unemployed $\quad 134 \quad 52.8$

Unskilled Labour $\quad 53 \quad 20.9$

Skilled Labour $\quad 35 \quad 13.8$

Professional (paper qualification) $\quad 32 \quad 12.6$

Average Monthly Income (Naira)
$\quad<\mathrm{N} 20,000$

$\mathrm{N} 20,000-\mathrm{N} 50,000 \quad 47 \quad 18.5$

$\mathrm{N} 51,000-\mathrm{N} 100,000 \quad 13 \quad 5.1$

$\mathrm{N} 101,000-\mathrm{N} 250,000 \quad 7 \quad 2.8$

Types of Family

$\begin{array}{lll}\text { Monogamous } & 178 & 70.1\end{array}$

$\begin{array}{lll}\text { Polygamous } & 74 & 29.1\end{array}$

Others (Divorced, Separated) $\quad 2 \quad 0.8$

\begin{tabular}{ccc} 
Number of wives in the family (n: 254$)$ & \\
1 & 178 & 70.1 \\
2 & 55 & 22.4 \\
3 & 17 & 6.7 \\
4 & 2 & 0.8 \\
\hline
\end{tabular}

Number of Children in the Family

\begin{tabular}{lcc}
$0-5$ & 227 & 89.4 \\
$6-10$ & 20 & 7.9 \\
$11-15$ & 5 & 2.0 \\
$16-20$ & 2 & 0.8 \\
urce of Health Care Financing & & \\
Out of pocket & 249 & 98.0 \\
Health Insurance & 5 & 2.0 \\
\hline
\end{tabular}




\section{In-law's support}

In $85(33.5 \%)$ of the participants, their in-laws provided them with adequate social support as against 169 (66.5\%) of the participants whose in-laws provided inadequate social support.

The details of level of social support among the study participants is shown in Table 2.

\section{Psychological distress among the study participants Prevalence of psychological distress among the study partici- pants}

A total of $203(79.9 \%)$ of the participants had psychological distress while 51 (20.1\%) had no psychological distress.

\section{The relationship between family social support and psychological well-being of infertile women Members of a social group}

Participants who did not belong to a social group that had psychological distress were $190(74.8 \%)$ as compared with those that belonged to a social group with psychological distress, $13(5.1 \%)$. However, belonging to a social group has no statistical significant relationship with psychological well-being (P-value $=0.796, \mathrm{c}^{2}$ $=1.021$ ).

\section{Husbands support}

The majority of the participants with psychological distress had adequate social support from their husbands $126(49.6 \%)$ as compared to those with psychological distress that had inadequate

Table 2. Level of social support among the study participants $(\mathrm{N}=254)$.

\begin{tabular}{lcc} 
Level of Social Support & Frequency ( $\mathrm{n})$ & Percentage (\%) \\
Membership of a social group & & \\
Religious Organisation & 2 & 0.8 \\
Cooperative Society & 3 & 1.2 \\
$\quad$ Professional group & 12 & 4.7 \\
$\quad$ None & 237 & 93.3 \\
Husband's support & & \\
$\quad$ Adequate & 172 & $67.7 \%$ \\
$\quad$ Inadequate & 82 & 32.3 \\
\hline In-law's support & & \\
Adequate & 85 & 33.5 \\
$\quad$ Inadequate & 169 & 66.5 \\
\hline
\end{tabular}

social support 77 (33.3\%). Social support by husbands therefore has a statistical significant relationship with psychological distress $\left(\mathrm{P}=0.000\right.$ and $\left.\mathrm{c}^{2}=14.021\right)$.

\section{In-laws support}

Participants with inadequate social support from in-laws 157 $(61.8 \%)$ that had psychological distress were more than those that had psychological distress with adequate social support from inlaws $46(18.1 \%)$. Therefore, there is a significant statistical relationship between social support from in-laws and psychological distress $\left(\mathrm{P}=0.000\right.$ and $\left.\mathrm{c}^{2}=53.006\right)$.

The relationship between family social support and psychological distress is shown in Table 3.

\section{Discussion}

\section{Level of social support among the study participants}

In this study, $93.3 \%$ of the infertile women were not members of any social group. This is in contrast to the study by JafarzadehKenarsari et al., in Iran, which showed support from social network is of importance in the life of infertile women. ${ }^{15}$

This difference would be due to cultural variation among the study participants in the study areas. the participants in this study belong to a culture that limits external socialization among females unlike the participants in the Iranian study where by Iranian Muslim women are permitted to belong to women social groups. The women in this study would presumably have to depend on their close family members for any form of social support since most of them did not belong to any social group.

$67.7 \%$ of participants confirmed that they had adequate social support from their husbands, while $66.5 \%$ had inadequate social support from their in-laws. This finding was similar with a study in Ilorin by Makanjuola et al., where majority of the participants had adequate social support from their husbands $(73.1 \%)^{16}$ but the contrast came up in the support provided by the in-laws $(33.5 \%)$ where it was below what the participants in the Ilorin study got from their in-laws.

The difference in the level of support from in-laws experienced by the participants in this study could be as a result of cultural variation where in the North-Western parts of Nigeria where the study was conducted, an infertile woman is named as juya (meaning a person with an empty womb) by the husband's family thereby

Table 3. Relationship between family social support and psychological well-being.

\begin{tabular}{|c|c|c|c|c|c|c|c|}
\hline Level of social support & Freq & Psychological distress & No psychological distress & Total & $\chi^{2}$ & Df & P-value \\
\hline $\begin{array}{l}\text { Members of a social group } \\
\text { Religious group } \\
\text { Cooperative society } \\
\text { Professional group } \\
\text { Total } \\
\text { No social group } \\
\text { Total }\end{array}$ & $\begin{array}{c}2 \\
3 \\
12 \\
17 \\
237 \\
254\end{array}$ & $\begin{array}{c}2 \\
2 \\
9 \\
13 \\
190 \\
203\end{array}$ & $\begin{array}{c}0 \\
1 \\
3 \\
4 \\
47 \\
51\end{array}$ & $\begin{array}{c}2 \\
3 \\
12 \\
17 \\
237 \\
254\end{array}$ & 1.021 & 3 & 0.796 \\
\hline $\begin{array}{l}\text { Husband support } \\
\text { Adequate } \\
\text { Inadequate } \\
\text { Total }\end{array}$ & $\begin{array}{c}172 \\
82 \\
254 \\
\end{array}$ & $\begin{array}{c}126 \\
77 \\
203 \\
\end{array}$ & $\begin{array}{c}46 \\
5 \\
51\end{array}$ & $\begin{array}{c}172 \\
82 \\
254 \\
\end{array}$ & 14.551 & 1 & 0.000 \\
\hline $\begin{array}{l}\text { Inlaws support } \\
\text { Adequate } \\
\text { Inadequate } \\
\text { Total } \\
\end{array}$ & $\begin{array}{c}85 \\
169 \\
254\end{array}$ & $\begin{array}{c}46 \\
157 \\
203\end{array}$ & $\begin{array}{l}39 \\
12 \\
51\end{array}$ & $\begin{array}{c}85 \\
169 \\
254\end{array}$ & 53.006 & 1 & 0.000 \\
\hline
\end{tabular}


encouraging him to marry more wives who could bear him children. This reduces the level of support she receives from the inlaws. In Southern Nigeria where Ilorin is situated, the mother inlaw is often the first person to ask why her daughter in-law has not conceived. She takes her to all sorts of health care givers including traditional healers and faith houses all in the bid for a child. ${ }^{17}$

\section{Relationship between family social support and psychological wellbeing}

In this study, psychological wellbeing has a significant relationship with husband $\left(\mathrm{P}=0.000\right.$ and $\left.\mathrm{c}^{2}=14.551\right)$ and in-laws support $\left(\mathrm{P}=0.000\right.$ and $\left.\mathrm{c}^{2}=53.006\right)$. This is consistent with a Portuguese study by Martins et al. where partner and family support had a strong direct relationship with infertility related stress. ${ }^{18}$ This similarity could probably be due to the fact that both group of study participants considering their infertile state require adequate support from family and friends which will have a positive effect on their mental health. Support from family can benefit a woman's adjustment when dealing with the stress of infertility.

A study among Japanese women by Akizuki et al. showed positive social support from husbands and in-laws. ${ }^{19}$ Hasanpour et al., in an Iranian study also revealed that infertile women received the most support from their families. ${ }^{20}$ In a study by Slade et al., among infertile women in Canada, social support had a positive effect on the mental health of the infertile women. ${ }^{21 Z C X}$

Social support helps women to think that they are not alone and can share their painful experiences with others so that they can relieve tension and anxiety. Also, supportive relationships provide a number of things that mitigate illness effect, including providing intimacy among couples and family members. It also provides a sense of belonging and reassurance of one's self worth and provides assistance, guidance, and advice.

\section{Conclusions}

Infertility places a lot of strain on relationships within families, friends and in-laws. Infertile women experience a change in interpersonal relationships and social interactions with their spouses and family members. Family social support could reduce the pressure imposed on women having infertility crisis and thus improve on their health outcome.

\section{References}

1. Mirzayi L, Gharamaleki N.S. Comparing perceived social support and life quality in fertile and infertile women. Int J Phys Beh Res 2015;4;290-4.

2. Faubion D. What is psychological distress? Ann over view, 2020. Available from: https://www.betterhelp.com/advice/grief/what-is-psychological-distress-an-overview/. Accessed: June 28th, 2020.

3. Erdem K. A sectional study: The relationship between perceived social support and depression in Turkish infertile women. Int J Fertil Steril 2014;8:303-14.
4. World Health Organisation (WHO). Prevention of mental disorders. Effective intervention and policy options. 2004 Summary Report. Available from: https://www.who.int/mental_health/evidence/en/prevention_of_mental_disorders_sr.pdf . Accessed: April 10th, 2019.

5. Greil A, Slauson K, Blevins K, McQuillan J. The experience of infertility: A review of recent literature. Sociol Health Ill 2010;32:140-62.

6. Mahmoudi MS, Mirzaian B, Hassanzadeh R. The relationship between social support and anxiety in infertile women. Turkish J Sci Res 2015;2:87-90.

7. Fooladvand KH. Effect of social support, academic stress and academic self-efficiency on physical, Psychological health. Contemp Psychol 2009;4:81-93.

8. Qadir F, Khalid A, Medhin G. Social support, marital adjustment and psychological distress among women with primary infertility in Pakistan. Women Health 2015;55:432-46.

9. Khoshbin A, Roshaninejad MD, Sabagh SH, Haghani H. Relationship between loneliness and social support in infertile couples. J Iranian Nurs Midwifery 2000;13:6.

10. Dyer SJ, Abraham N, Mokoena NE. Psychological distress among women suffering from infertility in South Africa; A quantitative assessment. Hum Reprod 2005;20:1938-43.

11. Kus C. Determination of the life quality and perceived social support of women in infertile case. Presented for M. Sc. Istanbul: Marmara University; 2008.

12. Eren N. The impact of the level of perceived social support in infertile couples on stress related with infertile and marital adjustment. Presented for Ph.D Ankara: Gazi University; 2008.

13. Goldberg D, Hillier V. A scaled version of the general health questionnaire. Psychol Med 1979;9:139-45.

14. EPI-INFO (Version 1.3)

15. Jafarzadeh-Kenarsari F, Ghahiri A, Habibi M, ZarghamBoroujeni A. Exploration of infertile couples support requirements: A qualitative study. Int. J Fertil Steril 2015;9:81-92.

16. Makanjuola AB, Elegbede AO, Abiosun OA. Predictive factors for psychiatric morbidity among women with infertility attending a gynaecology clinic in Nigeria. Afr $\mathrm{J}$ Psychiatry 2010;13:36-42.

17. Jessica U. Fertility in African culture and religion. 2010. Available from Stanford.edu.grp/womenscourse/fertilityafrican-culture-and-religion. Accessed: July 20th, 2015.

18. Martins MV, Peterson BD, Almeida VM, Costa ME. Direct and Indirect effects of perceived support on women's infertility related stress. Human Reproduction 2011;26:2113-21.

19. Akizuki Y, Kai I. Infertile Japanese women's perception of positive and negative social interactions with their social networks. Hum Reprod 2008;23:2737-43.

20. Hasanpoor-Azghdy SB, Simbar M, vedadhir A. A social consequences of infertility among Iranian women: A qualitative study. Int J Fertil Steril 2015;8:409-20.

21. Slade P, O’Neill C, Simpson AJ, Lashen H. The relationship between perceived stigma, disclosure patterns support and distress in new attendees at an infertility clinic. Hum Reprod 2007;22:2309-17. 